\title{
Dilute Alkali and Hydrogen Peroxide Treatment of Microwave Liquefied Rape Straw Residue for the Extraction of Cellulose Nanocrystals
}

\author{
Xingyan Huang, ${ }^{1,2}$ Cornelis F. De Hoop, ${ }^{1}$ Feng Li, ${ }^{2}$ Jiulong Xie, ${ }^{1,2}$ Chung-Yun Hse, \\ Jinqiu Qi, ${ }^{2}$ Yongze Jiang, ${ }^{2}$ and Yuzhu Chen ${ }^{2}$ \\ ${ }^{1}$ School of Renewable Natural Resources, Louisiana State University Agricultural Center, Baton Rouge, LA 70803, USA \\ ${ }^{2}$ College of Forestry, Sichuan Agricultural University, Chengdu, Sichuan 611130, China \\ ${ }^{3}$ Southern Research Station, USDA Forest Service, Pineville, LA 71360, USA \\ Correspondence should be addressed to Jiulong Xie; jxie6@lsu.edu
}

Received 27 October 2016; Revised 17 January 2017; Accepted 24 January 2017; Published 19 February 2017

Academic Editor: Jim Low

Copyright (c) 2017 Xingyan Huang et al. This is an open access article distributed under the Creative Commons Attribution License, which permits unrestricted use, distribution, and reproduction in any medium, provided the original work is properly cited.

Microwave-assisted liquefaction of rape straw in methanol was conducted to collect the liquefied residues for the extraction of cellulose nanocrystals (CNCs). The liquefied residue with content of $23.44 \%$ from $180^{\circ} \mathrm{C} / 7.5$ min was used to fibrillate CNCs with dilute alkali $(2 \% \mathrm{NaOH})$ and hydrogen peroxide $\left(5 \% \mathrm{H}_{2} \mathrm{O}_{2}\right)$ treatments, followed by ultrasonication for $15 \mathrm{~min}$. The FT-IR spectra and SEM images revealed that the liquefied residue from $180^{\circ} \mathrm{C} / 7.5 \mathrm{~min}$ exhibited a relatively homogeneous texture and a huge surface with cellulose as core structure. The retained hemicelluloses and other impurities in the liquefied residue were eliminated by $2 \% \mathrm{NaOH}$ treatment, and the surface and accessibility of the alkali treated sample were significantly increased by $5 \% \mathrm{H}_{2} \mathrm{O}_{2}$ treatment. The TEM images confirmed the CNCs had an average diameter of $12.59 \mathrm{~nm}$. The CNCs had good thermal stability with a maximum weight loss temperature of $376.5^{\circ} \mathrm{C}$.

\section{Introduction}

Nanocellulose has high reinforcing capabilities because of their unique characteristics including high tensile strength, high Young's modulus, high flexibility, and low coefficient of thermal expansion [1-4]. Previous studies have confirmed that agrowastes such as cotton stalks [5], soybean hulls [6], rice straw [7], banana peel [8], and wheat straw [9] are important sources for the isolation of nanocellulose. As an agrowaste from edible oil industry, large quantities of rape straw are annually produced, particularly in China. Though, value-added products such as composites [10], bioethanol [11], and biooil [12] have been produced from rape straw, no work has been reported on the isolation of CNCs from rape straw.

The plant cell wall is composed of cellulose and noncellulose such as hemicelluloses, lignin, pectin, and inorganic substance [13]. In the native cellulose fiber, individual CNCs are bonded by intermolecular forces and hydrogen bonds to each other [14]. The isolation of CNCs involves pretreatment to remove noncellulose components, followed by fibrillation of the bundles of microfibrils. Concentrated sodium hydroxide $(\mathrm{NaOH})$ and sulfuric acid combining with acidified sodium chlorite $\left(\mathrm{NaClO}_{2}\right)$ are the most commonly used pretreatment method to purify cellulose from plants [15, 16]. High-intensity ultrasonication has been widely applied to fibrillate CNCs due to its high efficiency to separate the fibrils from purified cellulose $[1,2]$.

Despite the successful isolation of CNCs from plant cell by the aforementioned processes, there are still problems such as long treatment time and environmental pollution because of the use of concentrated alkali or acid and the acidified sodium chlorite. In our previous studies, microwaveassisted liquefaction was applied in selectively liquefying noncellulose components in bamboo to extract holocellulose fibers and nanofibers [16-18]. This is because microwaveassisted liquefaction catalyzed by acid could remarkably 
eliminate lignin and hemicelluloses with a high cellulose content retaining in the liquefied residue. After liquefaction with mild conditions, the residues were almost composed of cellulose; even with severe conditions, the residues still exhibited a cellulose structure, which suggests a potential to extract CNCs from liquefied residues. Hydrogen peroxide $\left(\mathrm{H}_{2} \mathrm{O}_{2}\right)$, having been commonly applied for pulp bleaching, is a potential alternative for sodium chlorite because of its zero pollution. The HOO-group generated from $\mathrm{H}_{2} \mathrm{O}_{2}$ is the main oxygen compound for degrading lignin by reacting with quinine structures, double bonds, or carbonyl group in lignin, forming the soluble fragments of lignin $[19,20]$. As reported in previous study, alkaline hydrogen peroxide is an interesting alternative chlorine-free method to extract nanocrystalline cellulose from agroresidue [21].

Thus, the objective of the study is to use dilute alkali and hydrogen peroxide to purify the microwave liquefied rape straw residues in order to achieve an efficient approach for the extraction of CNCs from liquefied residues. The liquefied residue from a proper liquefaction reaction was collected and characterized for further usage. The dilute sodium hydroxide (2\%) and hydrogen peroxide (5\%) were employed in the purification treatment. The chemical treated samples were then subjected to high-intensity ultrasonication for nanofibrillation. The extracted nanocrystals as well as samples from each stage in the whole process were characterized. This study will provide a more environmental friendly approach for the isolation of nanocrystals and the integrated utilizations of rape straws.

\section{Experimental}

2.1. Material and Chemicals. The rape straws collected in Sichuan Province, China, were air dried and grinded into 20-40 mesh and then were oven-dried at $105^{\circ} \mathrm{C}$ until constant weight. All chemicals including sulfuric acid $\left(\mathrm{H}_{2} \mathrm{SO}_{4}\right)$, sodium hydroxide $(\mathrm{NaOH})$, and $30 \%$ hydrogen peroxide $\left(\mathrm{H}_{2} \mathrm{O}_{2}\right)$ were purchased from commercial sources without further purification.

2.2. Microwave Liquefaction. Liquefaction of rape straw was performed in a Milestone (Shelton, CT) MEGA laboratory microwave oven equipped with an ATC-400FO automatic fiber optic temperature control system. A typical run was carried out with the loading of $2 \mathrm{~g}$ of rape straw, $12 \mathrm{~g}$ of methanol, and $0.36 \mathrm{~g}$ of sulfuric acid. The mixed reactants were sealed in $100 \mathrm{~mL}$ Teflon reaction vessels with a magnetic stirring bar. The output power of the microwave energy was autoadjusted based on the temperature feedback from the sensor under maximum power of $700 \mathrm{~W}$. The sealed vessels were subjected to microwaves irradiation. The reaction temperature was increased from room temperature to the desired temperature (i.e., $140^{\circ} \mathrm{C}, 160^{\circ} \mathrm{C}$, and $180^{\circ} \mathrm{C}$ ) within $5 \mathrm{~min}$ and then maintained for 0 to $10 \mathrm{~min}$. The ice bath was applied to quench the reaction when the reaction is finished. After cooling, the liquefied products were dissolved in $150 \mathrm{~mL}$ of methanol under constant stirring for $4 \mathrm{~h}$ and filtered through Whatman number 4 filter paper to separate liquid and solid residue. The liquid portion was evaporated at $65^{\circ} \mathrm{C}$ under

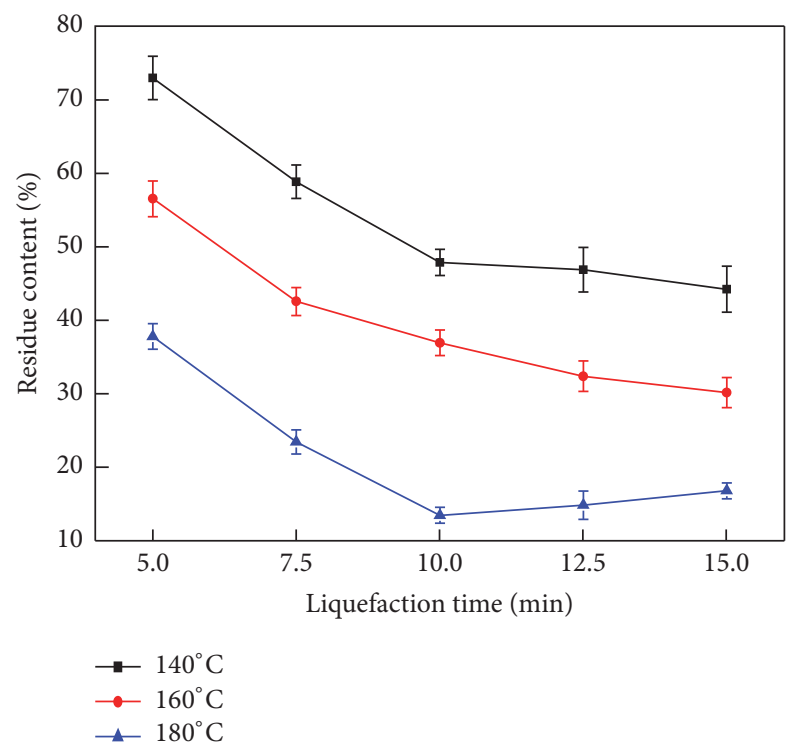

FIGURE 1: Liquefied residue contents with respect to liquefaction temperature and time (other conditions: methanol/rape straw, 6/1; sulfuric acid, 3\%).

vacuum to remove methanol. The gaseous products were vented because the yield of gaseous products was negligible. The residue that remained on the filter paper was oven-dried and weighed for the calculation of liquefied residue content as the following equation:

Liquefied residue content (\%)

$$
=\frac{\text { weight of residue }}{\text { weight of raw rape straw }} \times 100 \text {. }
$$

The liquefied residue contents from various reactions are presented in Figure 1.

2.3. Extraction of CNCs from Liquefied Residue. The liquefied residue was add to $2 \%(\mathrm{w} / \mathrm{v}) \mathrm{NaOH}$ solution with a solid to solvent ratio of $1: 30$ and maintained at $75^{\circ} \mathrm{C}$ for $1 \mathrm{~h}$ with constant stirring. The reaction was terminated by quenching with 10-fold ice water and the solution was centrifuged (6000 rpm at $5^{\circ} \mathrm{C}$ for $15 \mathrm{~min}$ ) to collect the sediment. The sediment was vacuum-filtered and washed with distilled water until its $\mathrm{pH}$ was neutral. The solid remained on the filter paper was bleached by $5 \% \mathrm{H}_{2} \mathrm{O}_{2}$ (solid/solvent, $1: 30$ ) at $75^{\circ} \mathrm{C}$ for $2.5 \mathrm{~h}$, followed by centrifugation and vacuum-filtration. The bleaching treatment was conducted twice. The chemical treatments were used to remove the phenolic compounds and eliminate traces of noncellulosic components. The hydrogen peroxide could also partially hydrolyze the amorphous cellulose.

The bleached sample was soaked in deionized water (concentration $0.05 \%$ ) and subjected to ultrasonic fibrillation by high-intensity ultrasonic processor equipped with a cylindrical titanium alloy probe with a diameter of $15 \mathrm{~mm}$. The process was performed at a frequency of $25 \mathrm{kHz}$ with an output power of $750 \mathrm{~W}$ at $60 \%$ amplitude for $15 \mathrm{~min}$. The 
ultrasonic treatment was carried out in ice bath throughout the process. The suspension obtained after ultrasonic treatment was centrifuged at rotate speed of $10000 \mathrm{rpm}$ for $15 \mathrm{~min}$ at $5^{\circ} \mathrm{C}$.

2.4. Characterization. Scanning electron microscope (SEM, JSM-6610 with $5-15 \mathrm{kV}$ accelerating voltage) was used to examine the morphology of the samples. Test samples were prepared for SEM inspection by coating gold using a vacuum sputter coater before being subjected to the SEM analysis.

Fourier transform infrared spectrometry (FT-IR) was used to study the chemical structure. The FT-IR analysis was performed on a Nicolet Nexus 670 spectrometer equipped with a Thermo Nicolet Golden Gate MKII Single Reflection ATR accessory. A small quantity of sample was covered flatwise on the detection window. Each sample was analyzed in the range of resolution from 400 to $4000 \mathrm{~cm}^{-1}$ with a spectral resolution of $4 \mathrm{~cm}^{-1}$ and total of 32 scans were collected.

The X-ray diffraction pattern was measured using Bruker/ Siemens D5000 X-ray automated powder X-ray diffractometer (Siemens Co., Wittelsbacherplatz, Munich, Germany) at ambient temperature. The detection was performed at a scan speed of $0.2^{\circ} / \mathrm{min}$ over the $2 \theta$ from 5 to $40^{\circ}$ with $\mathrm{Cu}-\mathrm{Ka}$ radiation $(\lambda=1.54 \AA)$ at $45 \mathrm{kV}$ and $40 \mathrm{~mA}$.

The morphology of CNCs was evaluated using transmission electron microscopy (TEM, JEOL 100CX, JEOL, Inc., Peabody, MA, USA) with an accelerating voltage of $80 \mathrm{kV}$. A droplet of diluted CNCs suspension was deposited on glow-discharged thin carbon-coated copper grids. The diameters of the CNCs were calculated form TEM images using microscope image analysis system (Image J) by randomly measuring 100 fibers.

The thermogravimetric and differential thermogravimetric (TG/DTG) analysis was conducted with a thermal analyzer Q50 TGA (TA Instruments, New Castle, DE) to simultaneously obtain thermogravimetric data. Each sample about $2 \mathrm{mg}$ was conducted at 25 to $800^{\circ} \mathrm{C}$ with constant heating rate of $20^{\circ} \mathrm{C} / \mathrm{min}$ under a flow of $60 \mathrm{~mL} / \mathrm{min}$ of nitrogen atmosphere.

\section{Results and Discussion}

\subsection{Characterization of Liquefied Residues}

3.1.1. FT-IR Spectra of Liquefied Residues. The FT-IR spectra of the raw rape straw and the liquefied residues from various liquefaction parameters are shown in Figure 2. The intensity of the broad peaks at around $3330 \mathrm{~cm}^{-1}$ owing to the $-\mathrm{OH}$ stretching vibration [22] varied with respect to the liquefaction conditions, revealing the release of hydroxyl groups as the liquefaction parameter was maintained at $180^{\circ} \mathrm{C} / 10 \mathrm{~min}$ (Figure 2(e)). By prolonging the reaction time, the content of hydroxyl groups was significantly reduced as indicated by the low intensity peak at $3330 \mathrm{~cm}^{-1}$. The prominent peaks at $1735 \mathrm{~cm}^{-1}$ was due to either the vibrations of acetyl and uronic ester groups in hemicelluloses or ester linkage of carboxylic group of the ferulic and p-coumaric acids of lignin and/or hemicelluloses [23]. It almost disappeared on the spectra of

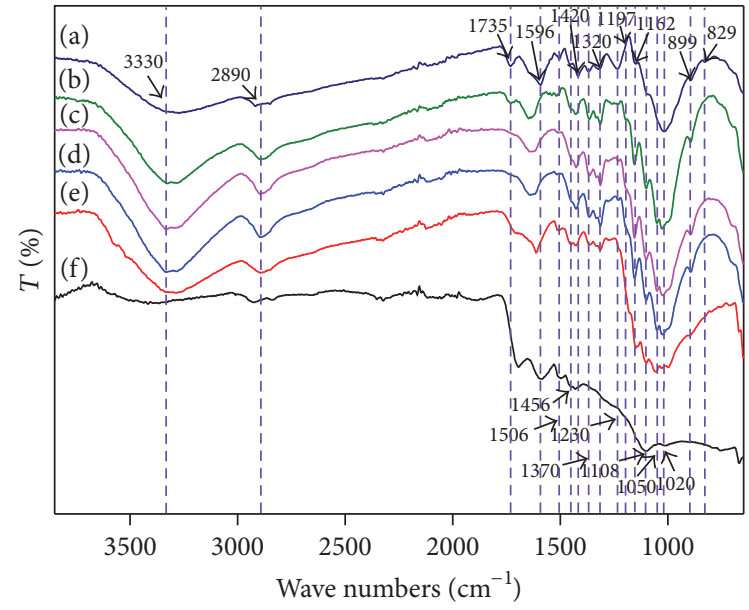

FIGURE 2: FT-IR transmittances of liquefied residues from different liquefactions: (a) raw rape straw; (b) $140^{\circ} \mathrm{C} / 15 \mathrm{~min}$; (c) $160^{\circ} \mathrm{C} / 15 \mathrm{~min}$; (d) $180^{\circ} \mathrm{C} / 7.5 \mathrm{~min}$; (e) $180^{\circ} \mathrm{C} / 10 \mathrm{~min}$; (f) $180^{\circ} \mathrm{C} / 15 \mathrm{~min}$ (other conditions: methanol/rape straw, $6 / 1$; sulfuric acid, $3 \%$ ).

the liquefied residue from $160^{\circ} \mathrm{C}$ for $15 \mathrm{~min}$ (Figure 2(c)). This result indicated the decomposition of hemicelluloses and lignin by breaking the carboxylic and ester bonds, rather than the disappearing of hemicelluloses and lignin [24]. However, it was intensified again in the spectra of residues from $180^{\circ} \mathrm{C} / 10 \mathrm{~min}$. One possibility for the represence of the peak at $1735 \mathrm{~cm}^{-1}$ was the esterification of the liquefied fragments.

As shown in Figure 2, the peaks at 1596 and $1506 \mathrm{~cm}^{-1}$ corresponding to $\mathrm{C}=\mathrm{C}$ skeletal vibration in aromatic rings, $1456 \mathrm{~cm}^{-1}$ arising from the $\mathrm{C}-\mathrm{H}$ bending, the band at $829 \mathrm{~cm}^{-1}$ assigned to two adjacent hydrogen atoms on the benzene ring [24], and the absorbance at $1230 \mathrm{~cm}^{-1}$ assigned to vibration of guaiacyl ring were from lignin [25]. Those characteristic peaks of lignin decreased as the reaction prolonged, indicating that the degradation of lignin increased. However, the peaks at 1596,1506 , and $1456 \mathrm{~cm}^{-1}$ became intensive at $180^{\circ} \mathrm{C} / 15 \mathrm{~min}$.

The peak at $1370 \mathrm{~cm}^{-1}$ attributing to phenolic $\mathrm{OH}$ groups [26] remarkably increased as the temperature increased to $180^{\circ} \mathrm{C}$ for $7.5 \mathrm{~min}$ (Figure $2(\mathrm{~d})$ ), then rapidly decreased, and disappeared with prolonging the reaction time $\left(180^{\circ} \mathrm{C} / 15 \mathrm{~min}\right)$ (Figure 2(f)).

The absorbance band at $1420 \mathrm{~cm}^{-1}$ arising from $\mathrm{C}-\mathrm{H}_{2}$ symmetric bending, the band at $1162 \mathrm{~cm}^{-1}$ due to C-O-C asymmetric stretching, $1320 \mathrm{~cm}^{-1}$ assigned to $\mathrm{CH}_{2}$ rocking vibration, the bands at 1108 and $1050 \mathrm{~cm}^{-1}$ corresponding to $\mathrm{C}-\mathrm{O}$ stretching, the $\mathrm{C}-\mathrm{O}-\mathrm{C}$ band at $1020 \mathrm{~cm}^{-1}$, and the $\mathrm{CH}$ deformation at $899 \mathrm{~cm}^{-1}$ were attributed to cellulose components $[24,27]$. Those bands became intensive at temperature of $180^{\circ} \mathrm{C}$ with less than $10 \mathrm{~min}$, while the intensity significantly decreased with increasing the time. This was because liquefaction enhanced the intensity of the cellulose bands by decomposing the lignin and hemicelluloses before temperature of $180^{\circ} \mathrm{C}$ for $7.5 \mathrm{~min}$; then cellulose begins to decompose resulting in the decreasing or absence of its functional groups. 


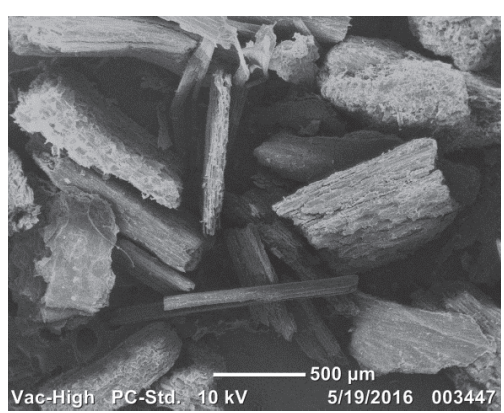

(a)

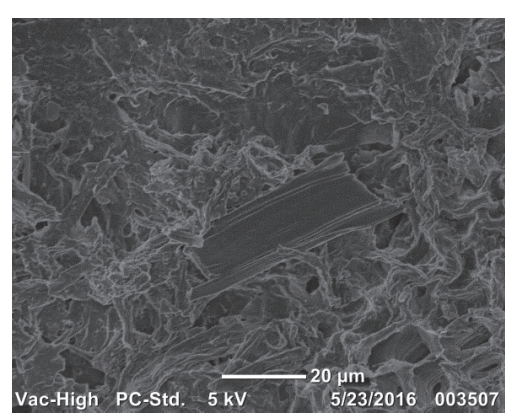

(d)

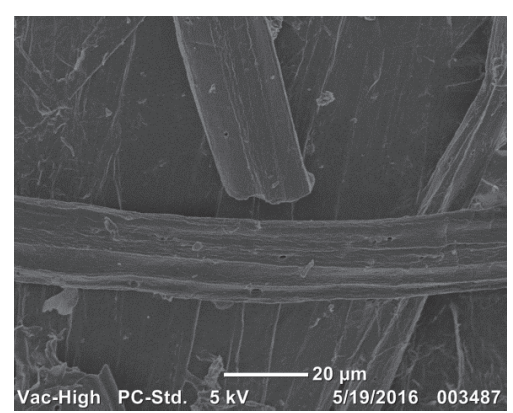

(b)

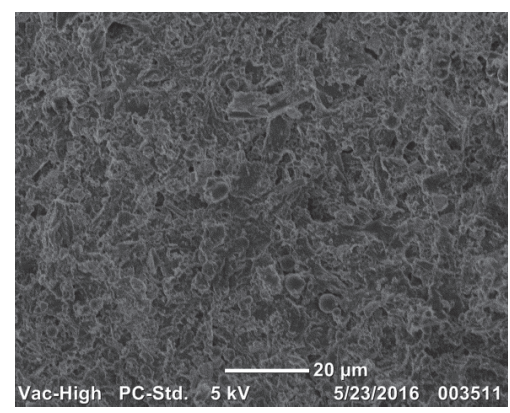

(e)

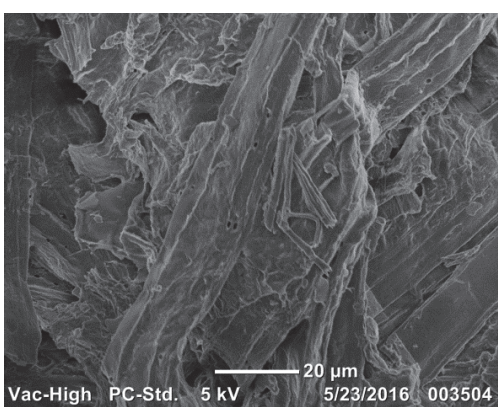

(c)

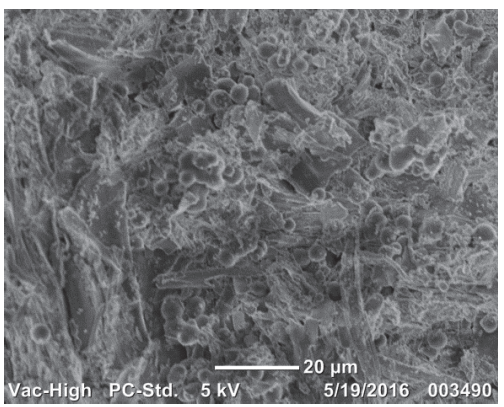

(f)

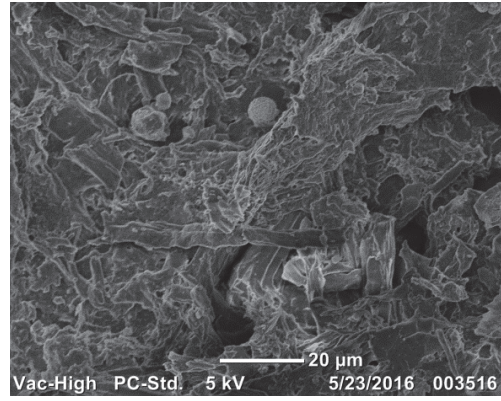

(g)

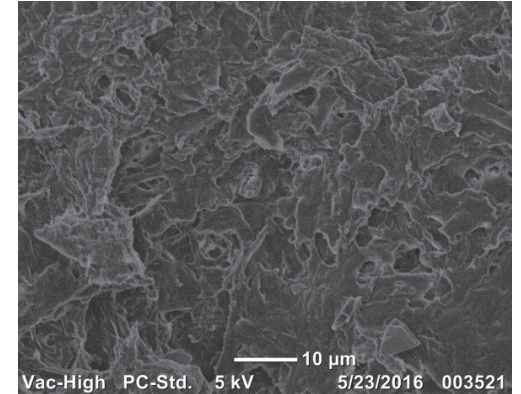

(h)

FIGURE 3: SEM images of liquefied residues from different liquefactions and chemical treatments: (a) raw rape straw; (b) $140^{\circ} \mathrm{C} / 15 \mathrm{~min}$; (c) $160^{\circ} \mathrm{C} / 15 \mathrm{~min}$; (d) $180^{\circ} \mathrm{C} / 7.5 \mathrm{~min}$; (e) $180^{\circ} \mathrm{C} / 10 \mathrm{~min}$; (f) $180^{\circ} \mathrm{C} / 15 \mathrm{~min}$; (g) $2 \% \mathrm{NaOH}$ for $1 \mathrm{~h}$; (h) $5 \% \mathrm{H}_{2} \mathrm{O}_{2}$ for $5 \mathrm{~h}$ (other liquefaction conditions: methanol/rape straw, 6/1; sulfuric acid, $3 \%$ ).

Specially, sulphate ester groups as evidenced by the bands at $1197 \mathrm{~cm}^{-1}$ corresponding to $\mathrm{S}=\mathrm{O}$ vibration were introduced to the liquefied residue during the liquefaction due to the use of sulfuric acid as the catalyst [28].

3.1.2. SEM Images of Liquefied Residues. The microstructure of the samples was characterized by SEM images (Figure 3). The SEM images evidenced the gradual removal of cementing materials around the fiber bundles such as hemicelluloses, lignin, and pectin by liquefaction. Very well-organized fiber bundles were observed on the images of the raw rape straw, which had a tough surface with many fragments (Figure 3(a)). The mean diameter for the raw rape straw was around $246 \pm$ $120.39 \mu \mathrm{m}$. As can be seen from Figure 3(b), the bundles were reduced into small fiber bundles coupling with 2-3 single fibers at $140^{\circ} \mathrm{C}$ for $15 \mathrm{~min}$, indicating the lignin in the middle lamella was partially removed. As elevating the temperature to $160^{\circ} \mathrm{C}$ for $15 \mathrm{~min}$ (Figure 3(c)), small fiber bundles were broken down to small irregular fragments. Figure $3(\mathrm{~d})\left(180^{\circ} \mathrm{C} / 7.5 \mathrm{~min}\right)$ showed the significant effect of temperature on the liquefaction extent by presenting a relatively homogeneous texture and a huge surface exposed the multilayer structure of single fiber wall, which was caused by the collapse of compact structure of the fiber. The significant influence of time was confirmed by Figure 3(e), which presents many uneven-sized spherical granule substances $(2.26 \pm 0.64 \mu \mathrm{m})$ on the surface. Generally, granule substance was ascribed to recondensed hemicelluloses/lignin derivatives. Besides, it may also attribute to the side-reaction by-product of acid-catalyzed hydrolysis of cellulose into levulinic acid [29]. Since the granule substance consisted mainly of humins and some unreacted cellulose [29], the yield of cellulose nanocrystals was speculated to be decreased by side-reaction. As the liquefaction prolonged to $15 \mathrm{~min}$ $\left(180^{\circ} \mathrm{C}\right.$, Figure $\left.3(\mathrm{f})\right)$, abundant aggregate spherical granules with diameter of $3.42 \pm 0.88 \mu \mathrm{m}$ were formed. It was proposed 


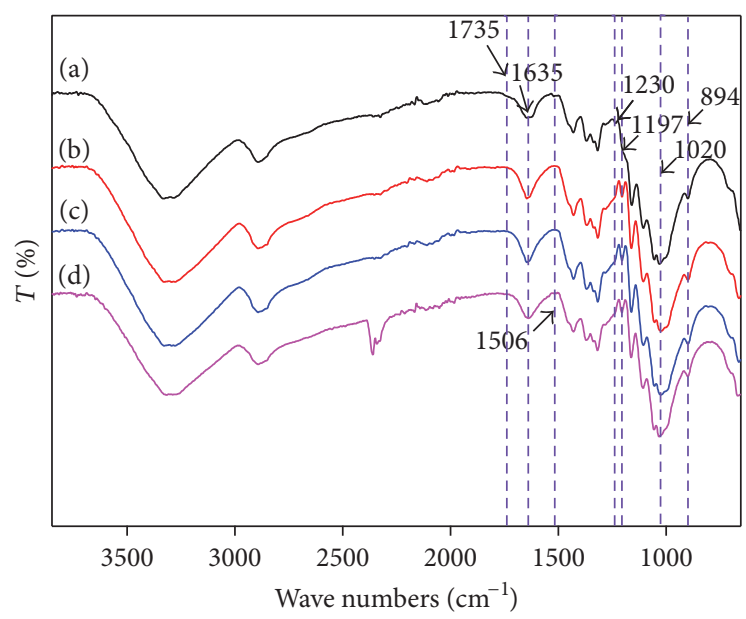

FIGURE 4: FT-IR transmittances of residues from different treatments: (a) $180^{\circ} \mathrm{C} / 7.5 \mathrm{~min}$; (b) $2 \% \mathrm{NaOH}$ for $1 \mathrm{~h}$; (c) $5 \% \mathrm{H}_{2} \mathrm{O}_{2}$ for $5 \mathrm{~h}$; (d) ultrasonication for $15 \mathrm{~min}$.

that a somewhat carbonization reaction of sugar derivatives occurred.

3.2. Extraction of CNCs from Liquefied Residue. The liquefied residue with content of $23.44 \%$ from $180^{\circ} \mathrm{C} / 7.5 \mathrm{~min}$ was used as raw material for the extraction of CNCs because the rape straw residue content was proper and still showed cellulosic structures as indicated by the FT-IR spectra and the SEM images. Chemical treatments were used to purify the residue for the extraction of CNCs. As compared with conventional liquefaction, microwave-assisted liquefaction could save more than $85 \%$ energy consumption [17], indicating that microwave heating has an energy advantage in liquefaction. By the referenced method [17], the energy consumption of rape straw liquefaction at $180^{\circ} \mathrm{C}$ for $7.5 \mathrm{~min}$ was $1.66 \times 10^{5} \mathrm{~J}$ (heating power of $378 \mathrm{~W}$ for $300 \mathrm{~s}$ plus maintaining power of $351 \mathrm{~W}$ for $150 \mathrm{~s})$.

Figure $3(\mathrm{~g})$ clearly shows that the spherical granules were exposed on the surface of the alkali treated samples, and the fibers became irregular and were much rougher in comparison with the liquefied residue. This is because of the removal of hemicelluloses. Generally, alkali can penetrate the interfiber region and cleave the $\alpha$-ether bonds between lignin and hemicelluloses, resulting in the removal of hemicelluloses and other impurities such as soluble lignin, pectin, and proteins $[30,31]$. The absence of band at $1735 \mathrm{~cm}^{-1}$ on the FT-IR spectrum of the alkali treated residue gave the evidence that the retained hemicelluloses in the liquefied residue had been completely removed by the alkali treatment (Figure 4(b)). Furthermore, the weaker absorption at $1230 \mathrm{~cm}^{-1}$ of alkali treated sample implied that most of the lignin in liquefied residue had been removed by treatment of $2 \% \mathrm{NaOH}$. With the removal of hemicelluloses and most of lignin, the purity of cellulose was enhanced remarkably, which was also reflected in the intensifying of the functional peak of absorbed water molecules at $1635 \mathrm{~cm}^{-1}$ [32].

However, the dark brown color of the liquefied residue remained unchanged after alkali treatment, suggesting that lignin fragments or carboxyl compounds introduced in the liquefaction process still existed, which formed a bridging bond with cellulose ester that prevents the separation of cellulose into individual fiber. Thus, it is necessary to bleach the alkali treated sample for further purification. Hydrogen peroxide (5\%) was used to bleach the alkali treated residue by eliminating the noncellulose components. The surface and accessibility of cellulose were significantly increased with presenting an even, smooth, and flat surface (Figure 3(h)). The application of $\mathrm{H}_{2} \mathrm{O}_{2}$ promoted the lignin removal and carboxyl compounds elimination indicated by the color changing from dark brown to pure. This is mainly because the oxidation reaction between $\mathrm{H}_{2} \mathrm{O}_{2}$ and lignin fragments or carboxyl compounds would enhance the degradation of lignin $[19,20]$.

The removal of noncellulose components with $2 \% \mathrm{NaOH}$ and $5 \% \mathrm{H}_{2} \mathrm{O}_{2}$ treatments contributed to the increase of sulphate ester band intensity at $1197 \mathrm{~cm}^{-1}$ (Figure $4(\mathrm{~b}$ and c)). Two absorption peaks at $1020 \mathrm{~cm}^{-1}$ and $894 \mathrm{~cm}^{-1}$ were observed in all the spectra which represented the typical structure of cellulose. They are attributed to C-O-C stretching vibrations and $\mathrm{C}-\mathrm{H}$ deformation of cellulose, respectively, and confirmed the presence of cellulose in all samples [24]. After chemical treatments, only $26.27 \%$ of the liquefied residue remained, suggesting that the liquefied residue contained a large amount of noncellulose components. $39.42 \%$ of the noncellulose components in the liquefied residue were removed first by $2 \% \mathrm{NaOH}$, and then $56.63 \%$ of the alkali treated residue was bleached by $5 \% \mathrm{H}_{2} \mathrm{O}_{2}$. This result also confirmed that the combination of alkali and hydrogen peroxide was efficient in eliminating the noncellulosic compounds in the liquefied rape straws residues.

The purified samples were subjected to ultrasonic nanofibrillation process, and $80.56 \%$ of the purified samples were defibrillated into nanocrystals by ultrasonic treatment for $15 \mathrm{~min}$. This result demonstrated that the ultrasonic was strong enough to defibrillate the chemical purified liquefied residue into nanocrystals. This was attributed to the fact that the ultrasonic treatment can break the hydrogen bonds and disintegrate microfibers into nanofibrils. Figure 4(d) elucidated that the chemical structure was not affected by the ultrasonic nanofibrillation process. Similar result was also observed on isolation of cellulose nanocrystals from banana peel using high-intensity ultrasonication [8].

As shown in the $\mathrm{X}$-ray diffraction patterns of raw rape straw and the liquefied residue from $180^{\circ} \mathrm{C} / 7.5 \mathrm{~min}$, the chemical purified cellulose and the nanocrystals obtained by ultrasonic treated for $15 \mathrm{~min}$, all specimens exhibited diffractograms typical of cellulose $\mathrm{I}$, with the main peaks at $2 \theta=16.2^{\circ}, 22.5^{\circ}$, and $34.5^{\circ}$ (Figure 5) [33]. This result indicated that the crystal structure of cellulose did not change during liquefaction and chemical and ultrasonic treatments. Those sharp peaks in the spectrum of liquefied residue (Figure 5(b)) were formed by the mineral matter such as calcium sulphate and quartz. The result was in accordance with the liquefaction of corn stover [34]. The calcium sulphate was generated by the reaction of sulfuric acid and calcium oxide that is main components in ashes [35]; beyond that, 


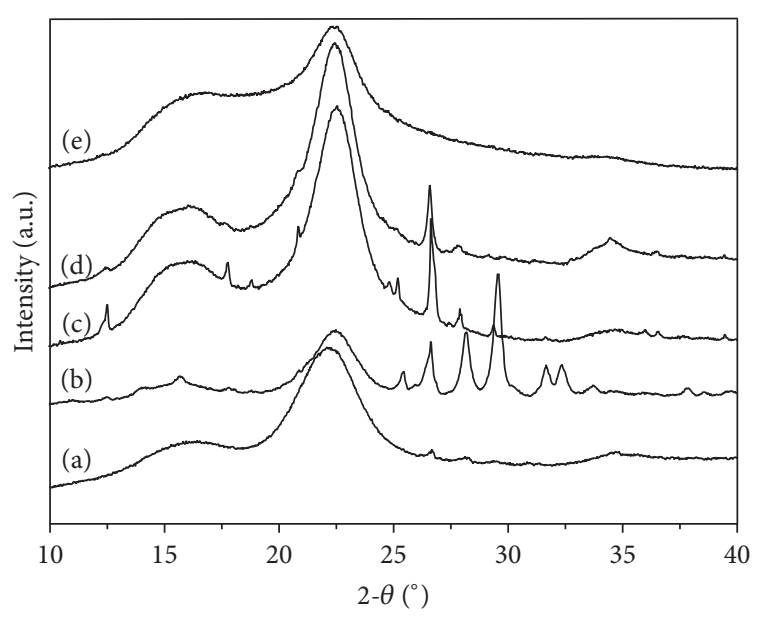

FIGURE 5: X-ray diffraction patterns of residues from different treatments: (a) raw rape straw; (b) $180^{\circ} \mathrm{C} / 7.5 \mathrm{~min}$; (c) $2 \% \mathrm{NaOH}$ for $1 \mathrm{~h}$; (d) $5 \% \mathrm{H}_{2} \mathrm{O}_{2}$ for $5 \mathrm{~h}$; (e) ultrasonication for $15 \mathrm{~min}$.

other sulphate crystals such as $\mathrm{K}_{2} \mathrm{SO}_{4}$ and $\mathrm{Na}_{2} \mathrm{SO}_{4}$ were formed during liquefaction [34]. In general, the quartz in the liquefied residue is derived from the naturally present $\mathrm{SiO}_{2}$ in rape straw. Though most of hemicelluloses and lignin were removed after liquefaction, the main cellulose crystalline intensities at $2 \theta=16.2^{\circ}$ and $22.5^{\circ}$ were weakened in comparison with raw rape straw. One possible reason was that the recondensed lignin still is a highly amorphous polymer and remained in liquefied residue, resulting in a decline of crystallinity degree [36].

\subsection{Characterization of CNCs}

3.3.1. TEM Images of CNCs. The TEM images as shown in Figure 6 confirmed the existence of the CNCs. As shown in Figure 6(a), individualized long fiber-like nanocrystals were observed. The diameter of the nanocrystals was $12.59 \pm$ $6.08 \mathrm{~nm}$. Meanwhile, opening up fiber-bundle was also observed in the TEM image, revealing that ultrasonic treatment did not completely separate the nanocrystals bundles (Figure 6(b)). Agglomeration of the individual nanocrystals was also found (Figure 6(c)). It might result from the drying process of the suspension during the TEM observations, while no agglomeration observed in the aqueous suspension was found even after quiescence for $72 \mathrm{~h}$ at $5^{\circ} \mathrm{C}$. This may be attributed to the introduction of sulphate ester groups during the liquefaction (confirmed by FT-IR spectra), which could provide negative electrostatic layer on the nanocrystals surface resulting in stable colloidal suspensions [37]. Moreover, intense mechanical forces of water also enhance the dispersibility of nanocrystals in aqueous suspension [33]. Almost $40 \%$ of the nanocrystals had a diameter within range of 5-10 nm, nearly $54 \%$ of the nanocrystals had diameter between 10 and $25 \mathrm{~nm}$, and only $7 \%$ of the nanocrystals had diameters higher than $25 \mathrm{~nm}$ or less than $10 \mathrm{~nm}$ (Figure 6(d)). Additionally, some granule substances were observed in the TEM image (Figure 6(c)). One plausible explanation for this result was that the micron-grade granule substances as presented in the above-mentioned SEM images were also reduced into nanoscale spheres with diameter around $14.48 \pm 4.92 \mathrm{~nm}$ by high-intensity ultrasonic waves, which provided strong mechanical oscillating power by producing violent shock within cavitation bubbles and the immediate surrounding area [2].

3.3.2. TG and DTG Cures. Thermogravimetric (TG) and differential thermogravimetric (DTG) cures of raw rape straw, liquefied residue $\left(180^{\circ} \mathrm{C} / 7.5 \mathrm{~min}\right), 2 \% \mathrm{NaOH}$ treated, $5 \% \mathrm{H}_{2} \mathrm{O}_{2}$ treated, and ultrasonic treated samples were shown in Figure 7. A slight weight loss in the region of $40-120^{\circ} \mathrm{C}$ was due to the evaporation of the humidity of materials or the low molecular weight compounds [33]. Compared with raw rape straw, the liquefied residue was more susceptible to thermal decomposition and higher weight loss at relatively low temperature as shown in DTG curves. This is attributable to lignin, having a relatively thermal stability in comparison with hemicelluloses and cellulose, which had been degraded during liquefaction [37]. Furthermore, for the liquefied residue, a weak weight loss peak was observed at $355^{\circ} \mathrm{C}$ in DTG cure, corresponding to the degradation of $\alpha$-cellulose [38]. Moreover, it is interesting to note that an apparent decomposition peak in the liquefied residue TG cure occurred at $733.3^{\circ} \mathrm{C}$, which might be attributed to degradation of granule substances that formed during liquefaction.

The maximum weight loss temperatures of the chemical treated and the ultrasonic treated samples occurred at 338.0 and $376.5^{\circ} \mathrm{C}$, respectively. Compared with the chemical treated samples, the nanocrystals had higher weight loss temperature and lower weight loss rate, which indicated that the ultrasonic treatment could enhance the thermal stability of nanocrystals. The liquefied residue had the maximum char yield $(21.46 \%)$ followed by chemical treated samples $(9.63 \%)$. This variation pattern was attributed to the removal of noncellulose during chemical treatments. Generally, the nanocrystals have minimum residue weight, because of the absence of nonorganic components in the nanocrystals [15]. However, in this work, the minimum residual weight (4.61\%) was observed from raw rape straw, rather than nanocrystals $(6.82 \%)$. This was possible associated with the presence of nanoscale granule substances in CNCs. The high thermal stability of nanocrystals isolated from rape straw could expand its applicability for biocomposites.

\section{Conclusions}

Cellulose nanocrystals (CNCs) were successfully extracted from liquefied residues through treatments of dilute alkali and hydrogen peroxide combining high-intensity ultrasonication. Most of lignin and hemicelluloses in the liquefied residues from $180^{\circ} \mathrm{C} / 7.5 \mathrm{~min}$ were removed during the liquefaction, resulting in cellulose as core structure, which was confirmed by the FT-IR spectra and SEM images. The retained hemicelluloses and impurities in the liquefied residue were eliminated by $2 \% \mathrm{NaOH}$ and $5 \% \mathrm{H}_{2} \mathrm{O}_{2}$ treatments. The surface and accessibility of the alkali treated samples were significantly increased by $5 \% \mathrm{H}_{2} \mathrm{O}_{2}$ treatment. 


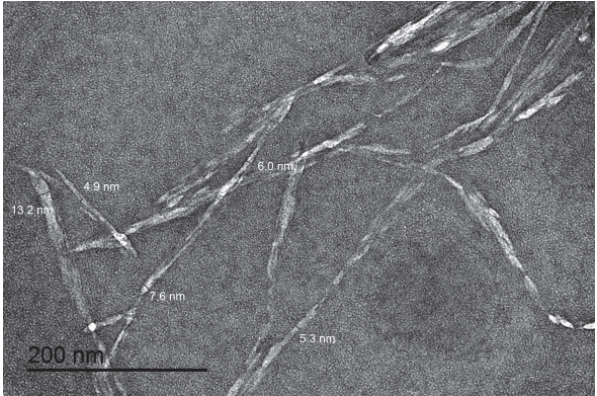

(a)

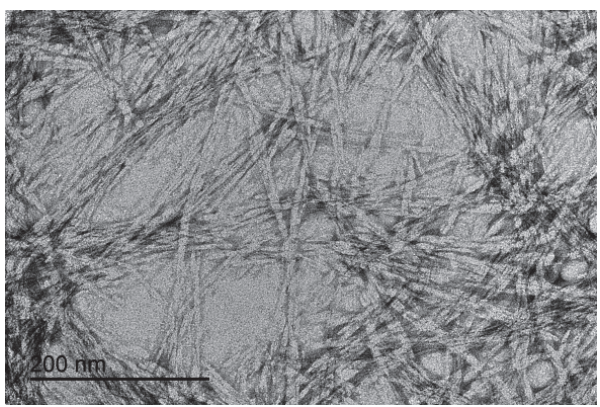

(c)

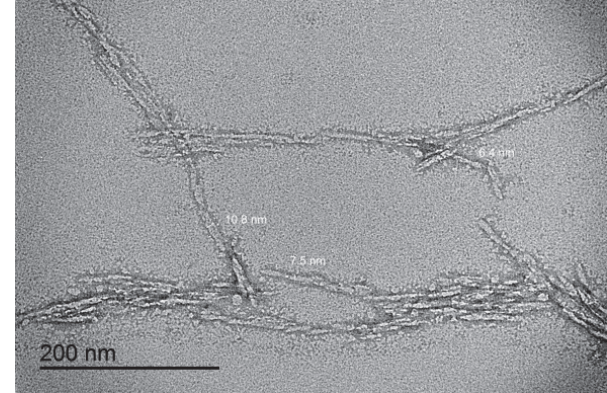

(b)

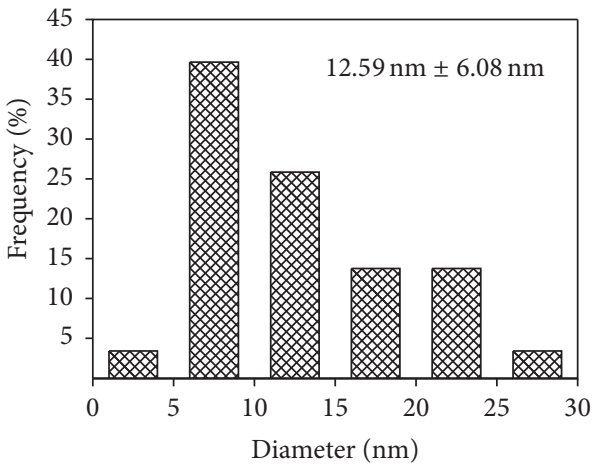

(d)

FIGURE 6: TEM images and diameter distribution of CNCs: (a) individualized CNCs; (b) opening up fiber-bundle; (c) reticular nanostructure; (d) diameter distribution.
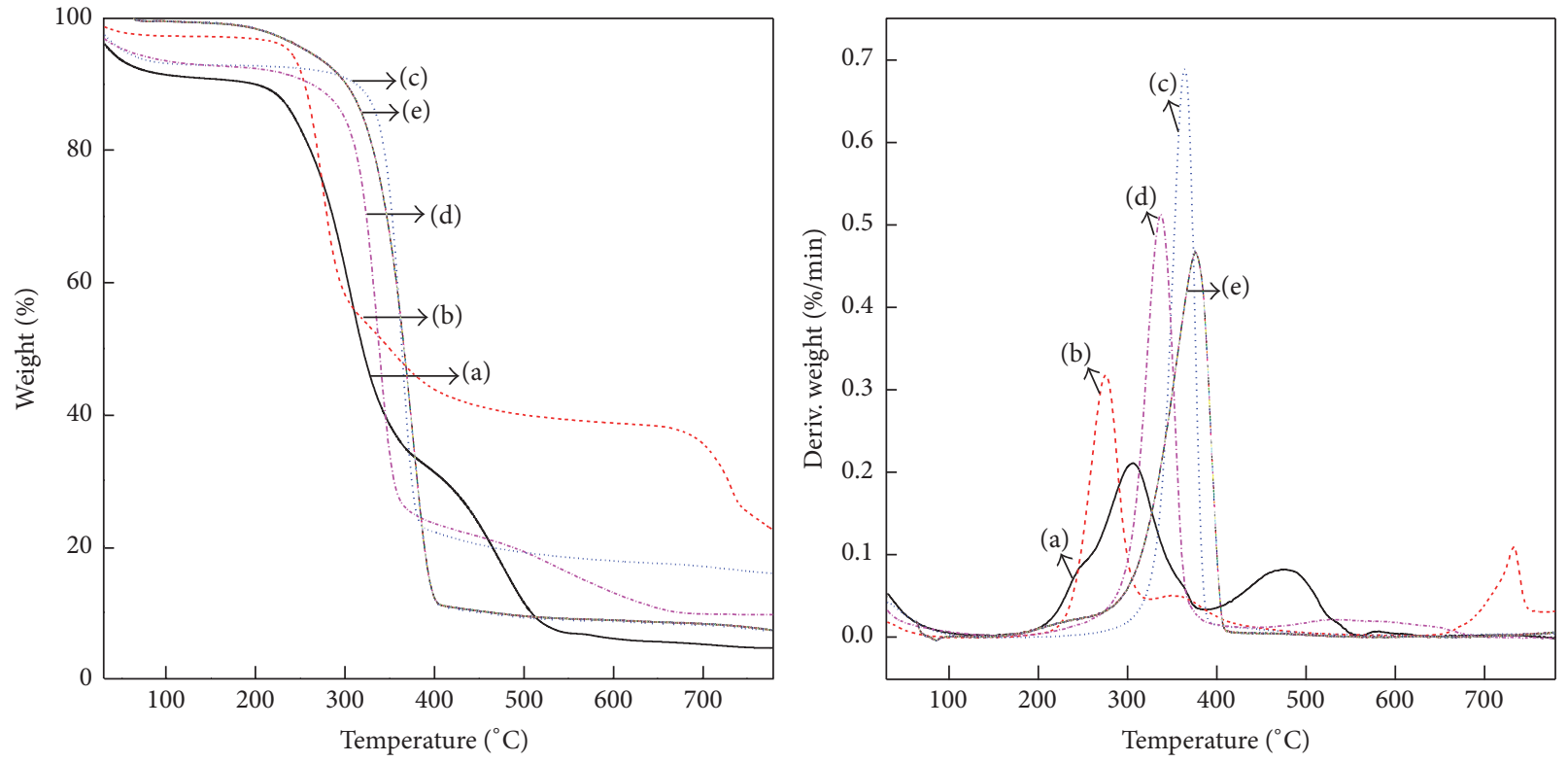

Figure 7: TG and DTG curves of residues from different treatments: (a) raw rape straw; (b) $180^{\circ} \mathrm{C} / 7.5 \mathrm{~min}$; (c) $2 \% \mathrm{NaOH}$ for $1 \mathrm{~h}$; (d) $5 \% \mathrm{H}_{2} \mathrm{O}_{2}$ for $5 \mathrm{~h}$ and ultrasonication for $15 \mathrm{~min}$. 
With high-intensity ultrasonic nanofibrillation treatment, CNCs with an average diameter of $12.59 \mathrm{~nm}$ were obtained from chemical purified samples. Thermogravimetric analysis demonstrated that CNCs had good thermal stability.

\section{Competing Interests}

The authors declare there is no conflict of interests regarding the publication of this paper.

\section{Acknowledgments}

This work is funded by the USDA Forest Service 2015 Wood Innovations Funding Opportunity program, Agreement 15DG-11083150-054. The authors also appreciate the financial support from China Scholarship Council.

\section{References}

[1] W. Chen, H. Yu, Y. Liu, Y. Hai, M. Zhang, and P. Chen, "Isolation and characterization of cellulose nanofibers from four plant cellulose fibers using a chemical-ultrasonic process," Cellulose, vol. 18, no. 2, pp. 433-442, 2011.

[2] W. Chen, H. Yu, Y. Liu, P. Chen, M. Zhang, and Y. Hai, "Individualization of cellulose nanofibers from wood using high-intensity ultrasonication combined with chemical pretreatments," Carbohydrate Polymers, vol. 83, no. 4, pp. 1804-1811, 2011.

[3] S. Ren, X. Sun, T. Lei, and Q. Wu, "The effect of chemical and high-pressure homogenization treatment conditions on the morphology of cellulose nanoparticles," Journal of Nanomaterials, vol. 2014, Article ID 582913, 11 pages, 2014.

[4] A. R. Kakroodi, S. Cheng, M. Sain, and A. Asiri, "Mechanical, thermal, and morphological properties of nanocomposites based on polyvinyl alcohol and cellulose nanofiber from Aloe vera rind," Journal of Nanomaterials, vol. 2014, Article ID 903498, 7 pages, 2014.

[5] B. Soni, E. B. Hassan, and B. Mahmoud, "Chemical isolation and characterization of different cellulose nanofibers from cotton stalks," Carbohydrate Polymers, vol. 134, pp. 581-589, 2015.

[6] A. Ferrer, C. Salas, and O. J. Rojas, "Physical, thermal, chemical and rheological characterization of cellulosic microfibrils and microparticles produced from soybean hulls," Industrial Crops and Products, vol. 84, pp. 337-343, 2016.

[7] F. Jiang, T. Kondo, and Y.-L. Hsieh, "Rice straw cellulose nanofibrils via aqueous counter collision and differential centrifugation and their self-assembled structures," ACS Sustainable Chemistry \& Engineering, vol. 4, no. 3, pp. 1697-1706, 2016.

[8] P. Khawas and S. C. Deka, "Isolation and characterization of cellulose nanofibers from culinary banana peel using highintensity ultrasonication combined with chemical treatment," Carbohydrate Polymers, vol. 137, pp. 608-616, 2016.

[9] M. Singh, A. Kaushik, and D. Ahuja, "Surface functionalization of nanofibrillated cellulose extracted from wheat straw: effect of process parameters,' Carbohydrate Polymers, vol. 150, pp. 48-56, 2016.

[10] L. Huang, P. Xia, Y. Liu et al., "Production of biodegradable board using rape straw and analysis of mechanical properties," BioResources, vol. 11, no. 1, pp. 772-785, 2016.

[11] M. Lewandowska, K. Szymańska, N. Kordala, A. Dabrowska, W. Bednarski, and A. Juszczuk, "Evaluation of Mucor indicus and Saccharomyces cerevisiae capability to ferment hydrolysates of rape straw and Miscanthus giganteus as affected by the pretreatment method," Bioresource Technology, vol. 212, pp. 262-270, 2016.

[12] Y. Fan, Y. Cai, X. Li et al., "Rape straw as a source of biooil via vacuum pyrolysis: optimization of bio-oil yield using orthogonal design method and characterization of bio-oil," Journal of Analytical and Applied Pyrolysis, vol. 106, pp. 63-70, 2014.

[13] A. Kaushik and M. Singh, "Isolation and characterization of cellulose nanofibrils from wheat straw using steam explosion coupled with high shear homogenization," Carbohydrate Research, vol. 346, no. 1, pp. 76-85, 2011.

[14] R. Shinoda, T. Saito, Y. Okita, and A. Isogai, "Relationship between length and degree of polymerization of TEMPOoxidized cellulose nanofibrils," Biomacromolecules, vol. 13, no. 3, pp. 842-849, 2012.

[15] M. Li, L.-J. Wang, D. Li, Y.-L. Cheng, and B. Adhikari, "Preparation and characterization of cellulose nanofibers from depectinated sugar beet pulp," Carbohydrate Polymers, vol. 102, no. 1, pp. 136-143, 2014.

[16] J. Xie, C.-Y. Hse, C. Li et al., "Characterization of microwave liquefied bamboo residue and its potential use in the generation of nanofibrillated cellulosic fiber," ACS Sustainable Chemistry \& Engineering, vol. 4, no. 6, pp. 3477-3485, 2016.

[17] J. Xie, C.-Y. Hse, T. F. Shupe, H. Pan, and T. Hu, "Extraction and characterization of holocellulose fibers by microwave-assisted selective liquefaction of bamboo," Journal of Applied Polymer Science, vol. 133, no. 18, 2016.

[18] J. Xie, C.-Y. Hse, C. F. De Hoop, T. Hu, J. Qi, and T. F. Shupe, "Isolation and characterization of cellulose nanofibers from bamboo using microwave liquefaction combined with chemical treatment and ultrasonication," Carbohydrate Polymers, vol. 151, pp. 725-734, 2016.

[19] Y. Ni and Z. He, "Review: using magnesium hydroxide as the alkali source for peroxide bleaching of mechanical pulpsprocess chemistry and industrial implementation," Nordic Pulp \& Paper Research Journal, vol. 25, no. 2, pp. 170-177, 2010.

[20] W. Gong, C. Liu, X. Mu et al., "Hydrogen peroxide-assisted sodium carbonate pretreatment for the enhancement of enzymatic saccharification of corn stover," ACS Sustainable Chemistry \& Engineering, vol. 3, no. 12, pp. 3477-3485, 2015.

[21] F. I. Ditzel, E. Prestes, B. M. Carvalho, I. M. Demiate, and L. A. Pinheiro, "Nanocrystalline cellulose extracted from pine wood and corncob," Carbohydrate Polymers, vol. 157, pp. 1577-1585, 2017.

[22] M. Sain and S. Panthapulakkal, "Bioprocess preparation of wheat straw fibers and their characterization," Industrial Crops and Products, vol. 23, no. 1, pp. 1-8, 2006.

[23] W. P. Flauzino Neto, H. A. Silvério, N. O. Dantas, and D. Pasquini, "Extraction and characterization of cellulose nanocrystals from agro-industrial residue-soy hulls," Industrial Crops and Products, vol. 42, no. 1, pp. 480-488, 2013.

[24] G. Li, C.-Y. Hse, and T. Qin, "Wood liquefaction with phenol by microwave heating and FTIR evaluation," Journal of Forestry Research, vol. 26, no. 4, pp. 1043-1048, 2015.

[25] M. Poletto, A. J. Zattera, and R. M. C. Santana, "Structural differences between wood species: evidence from chemical composition, FTIR spectroscopy, and thermogravimetric analysis," Journal of Applied Polymer Science, vol. 126, no. 1, pp. E336-E343, 2012. 
[26] M. G. Alriols, A. Tejado, M. Blanco, I. Mondragon, and J. Labidi, "Agricultural palm oil tree residues as raw material for cellulose, lignin and hemicelluloses production by ethylene glycol pulping process," Chemical Engineering Journal, vol. 148, no. 1, pp. 106114, 2009.

[27] A. Alemdar and M. Sain, "Biocomposites from wheat straw nanofibers: morphology, thermal and mechanical properties," Composites Science and Technology, vol. 68, no. 2, pp. 557-565, 2008.

[28] P. Lu and Y.-L. Hsieh, "Preparation and properties of cellulose nanocrystals: rods, spheres, and network," Carbohydrate Polymers, vol. 82, no. 2, pp. 329-336, 2010.

[29] B. Girisuta, L. P. B. M. Janssen, and H. J. Heeres, "A kinetic study on the decomposition of 5-hydroxymethylfurfural into levulinic acid," Green Chemistry, vol. 8, no. 8, pp. 701-709, 2006.

[30] C. S. Junior, A. M. F. Milagres, A. Ferraz, and W. Carvalho, "The effects of lignin removal and drying on the porosity and enzymatic hydrolysis of sugarcane bagasse," Cellulose, vol. 20, no. 6, pp. 3165-3177, 2013.

[31] N. L. Garcia de Rodriguez, W. Thielemans, and A. Dufresne, "Sisal cellulose whiskers reinforced polyvinyl acetate nanocomposites," Cellulose, vol. 13, no. 3, pp. 261-270, 2006.

[32] A. Mtibe, L. Z. Linganiso, A. P. Mathew, K. Oksman, M. J. John, and R. D. Anandjiwala, "A comparative study on properties of micro and nanopapers produced from cellulose and cellulose nanofibres," Carbohydrate Polymers, vol. 118, pp. 1-8, 2015.

[33] H. Liu, D. Liu, F. Yao, and Q. Wu, "Fabrication and properties of transparent polymethylmethacrylate/cellulose nanocrystals composites," Bioresource Technology, vol. 101, no. 14, pp. 56855692, 2010.

[34] W. Xiao, L. Han, and Y. Zhao, "Comparative study of conventional and microwave-assisted liquefaction of corn stover in ethylene glycol," Industrial Crops and Products, vol. 34, no. 3, pp. 1602-1606, 2011.

[35] J. Capablo, P. A. Jensen, K. H. Pedersen et al., "Ash properties of alternative biomass," Energy \& Fuels, vol. 23, no. 4, pp. 19651976, 2009.

[36] H. Pan, T. F. Shupe, and C.-Y. Hse, "Characterization of liquefied wood residues from different liquefaction conditions," Journal of Applied Polymer Science, vol. 105, no. 6, pp. 3739-3746, 2007.

[37] D. Bondeson and K. Oksman, "Dispersion and characteristics of surfactant modified cellulose whiskers nanocomposites," Composite Interfaces, vol. 14, no. 7-9, pp. 617-630, 2007.

[38] C. J. Chirayil, J. Joy, L. Mathew, M. Mozetic, J. Koetz, and S. Thomas, "Isolation and characterization of cellulose nanofibrils from Helicteres isora plant," Industrial Crops and Products, vol. 59, pp. 27-34, 2014. 

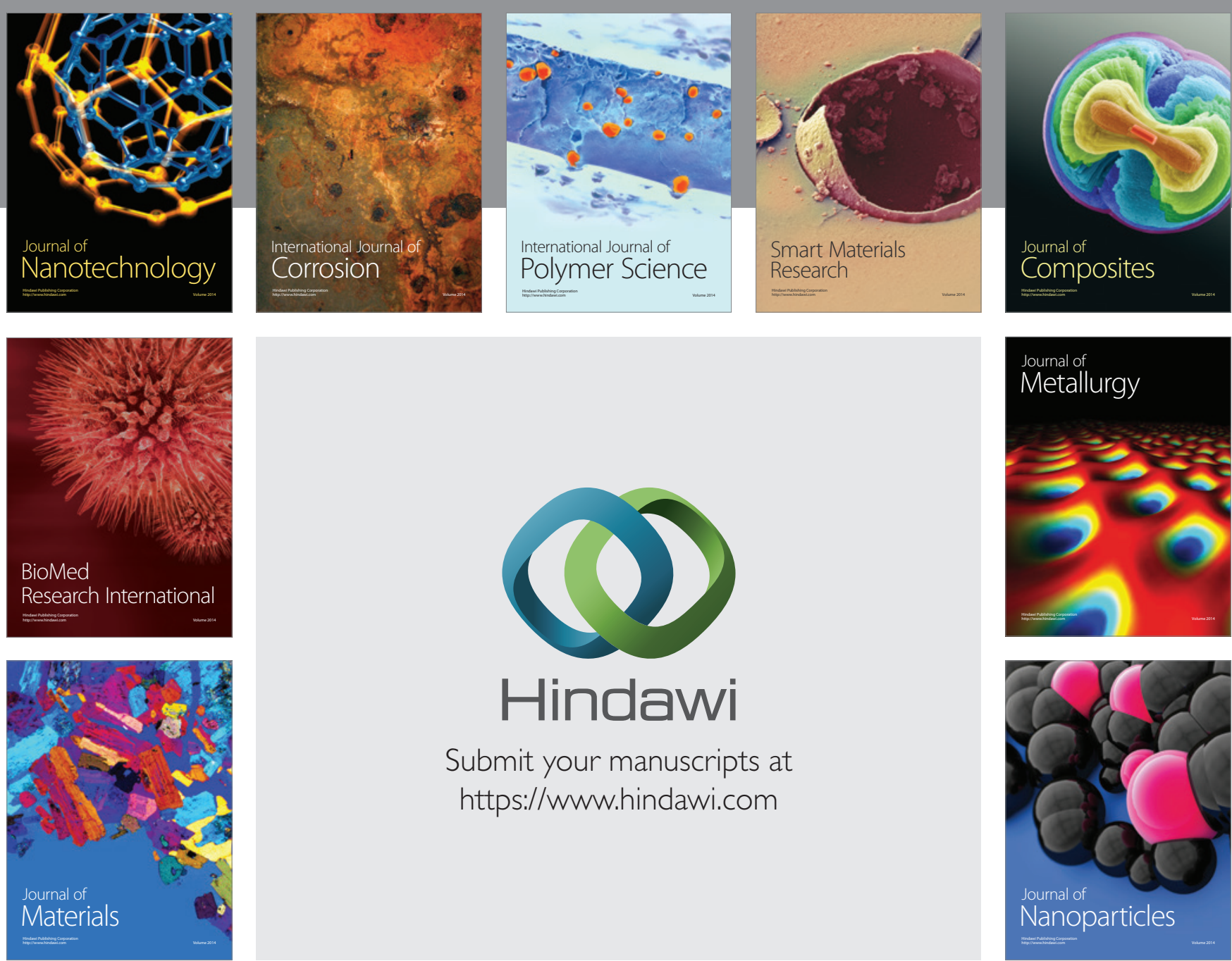

\section{Hindawi}

Submit your manuscripts at

https://www.hindawi.com

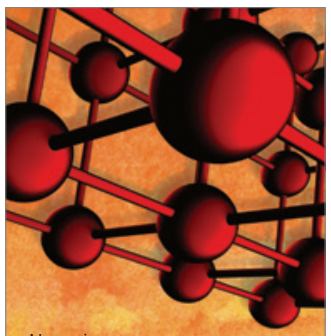

Materials Science and Engineering
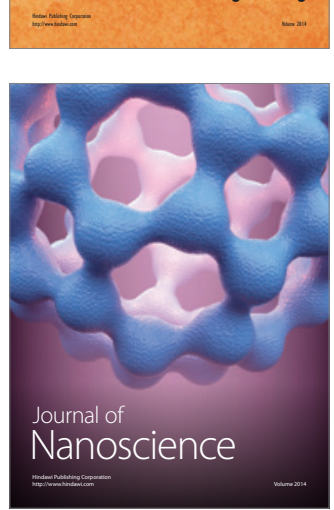
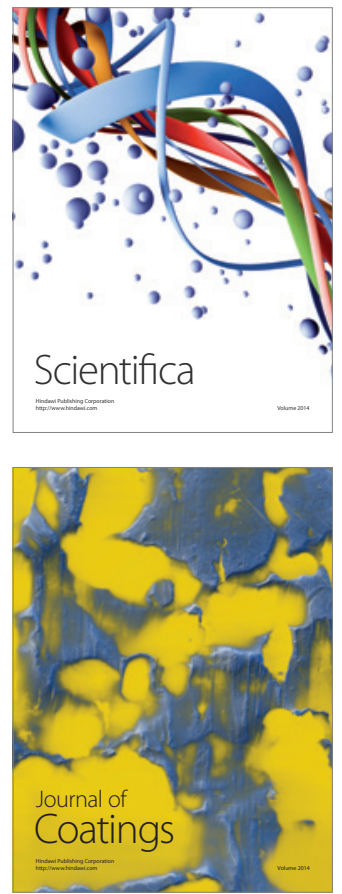
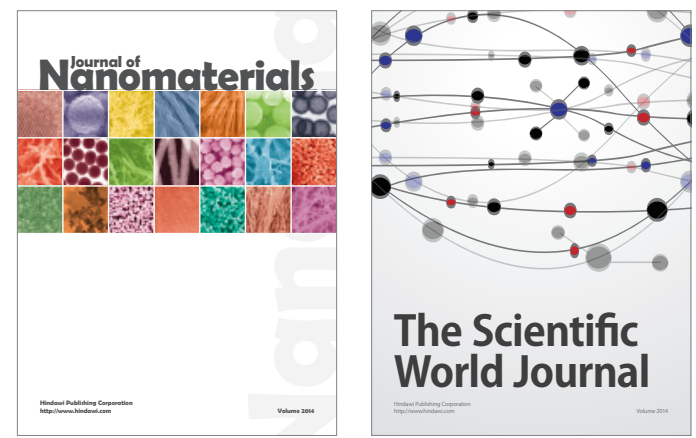

The Scientific World Journal
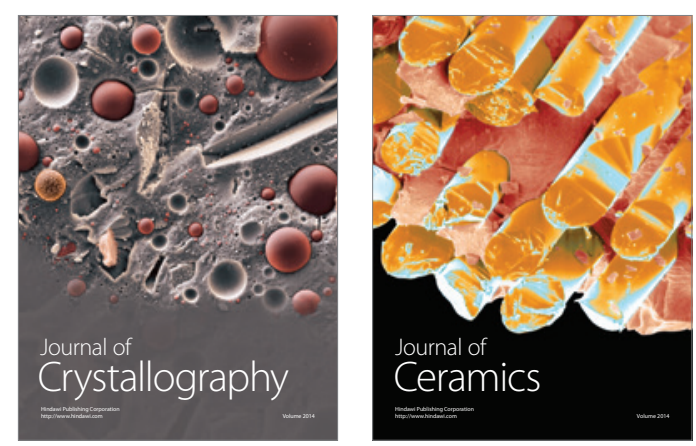
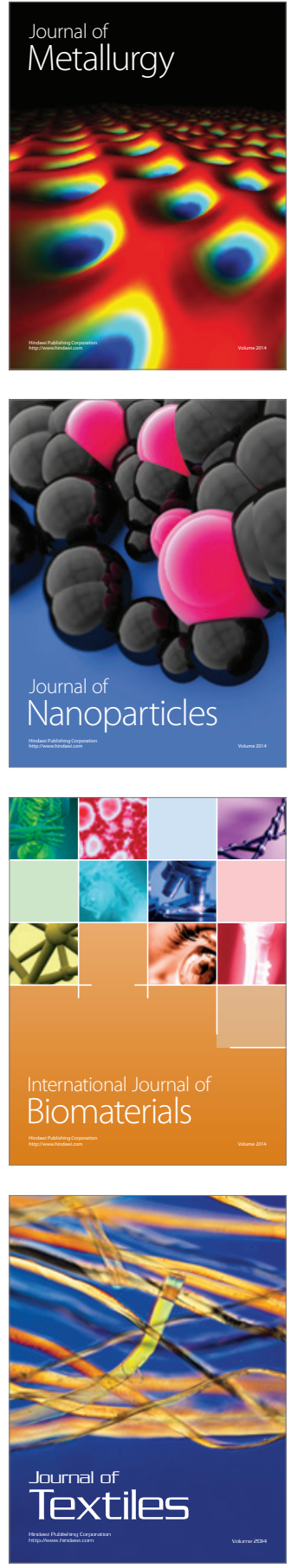